\title{
Smart aspects of conserving the integration between buildings inside the existing urban context
}

\author{
Dr. Gehan Ahmed
}

\begin{abstract}
In the past era, the aspects of integrating the new building with the existing one appeared to be concerning the outer appearance or features of the tradition urban context. After the call of for sustainable development, the aspect of designing the building varies to suit the sustainability. So, Smart sustainable preservation is about evolving our existing building stock, instead of razing and building new. At the same time, the intelegancy of the materials and the aspect of the intelligent building seems to accomplish the need of sustainability, as intelligence actually is a mental and sensitive deal with the matter which promotes motion and actions to solve much issues concerning it, but within these aspects their aren't a clear criterion to deal with old spaces in a smart manner without losing its style and taste. On the other hand, there aren't a fully respect for the future response of the urban design of such old sites which could be treated in such a smart manner. So the liability issue is : $\mathbf{1}^{\text {st }}$ concerns the search for the main conventional applications that could be followed to support the presence of new buildings placed in these places but defiantly in a smart manner supposing that using techniques and tools being developed today to make complete high performance products is one of the main hypothesis that could be followed and the 2 nd one is the multi functioning of any element of the space .The followed methodology is measurable where measuring the main approaches applied in the smart or the intelligent aspects to deduce the main aspects that must be used to inform the integration between the new building and the tradition urban context.
\end{abstract}

Key words: Smart aspects, urban context, sustainability, integration, clever system, performance.

أصبح الاهتمام فى الأونه الأخيرة بتحقيق التكامل بين المباني الجديدة والمباني القديمة داخل المحيط العمر اني بقتصر فقط على الثنكل

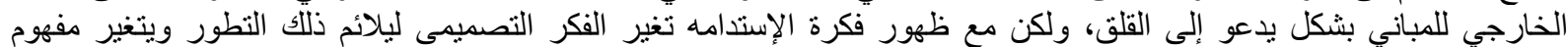

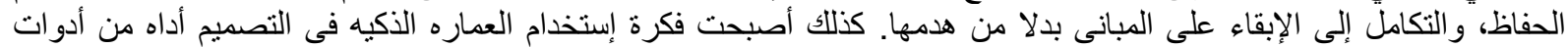

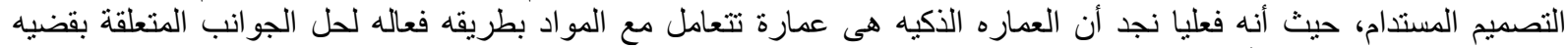

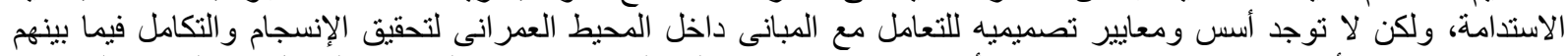

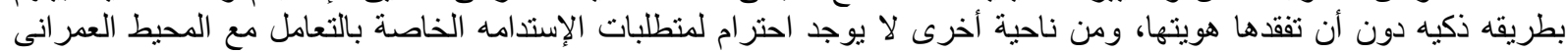

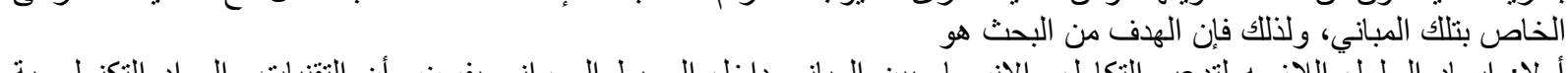

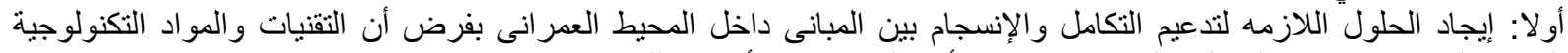

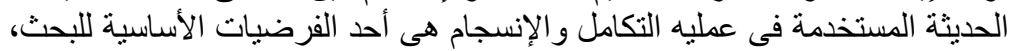

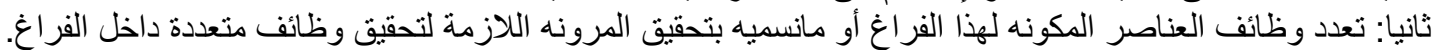

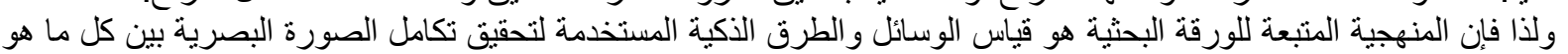
قائم أو جديد داخل المحيط العمر انى. الكلمات المفتاحية: الجو انب الذكبه، المحيط العمر انى، الإستدامه، التكامل و الإنسجام، أنظمه ذكيه، أداء

\section{The Introduction}

Both then and now, architecture is the arbitration between techniques, images, and the panorama of culture that presents at every instant. So there will be a struggle between the past and the new to reach the norm of the era, referring to the means of integration between the old and the new one. As there are two options while integrating places: integration through harmony, or integration through contrast. As the advantage of using the harmonious 
approach is that it keeps the character of the place, and this can be achieved through assimilation of the style, scale, morphology, construction finishing details of the old buildings. Another option is using current events to link the new with the old, respecting the skyline and area building codes which should create good solutions. Another way is by making mental relations to the history of the place, and symbolic architecture .On the other hand the integration through contrast depends on the power of exploring the unknown and new ideas and ways of solving problems. This can be achieved through the use of transparency, hiding under ground, separating old from new, or making an unusual new building in the existing classical site if the new is a real important building politically or socially [1]. Building's conservation for the $21^{\text {st }}$ century varies as it will focus on the sustainability issue, to sustain the use of older buildings rather than protecting them from change [2]. Today, architects are beginning to look forward to using the developments of technology which seems to be smart or intelligent, because smart materials brings new solutions to long-standing problems that involved in developing new building functions, forms, and responses. As they have wide variety kinds which have great probability for using in architecture. Moreover dramatically reduce the energy and material cost of the buildings, enables the human to design direct and discrete environments that provide better conditions in space for human occupants [3]. But to what level the intelligence could support the existing places specially while integrating the new with the old?

So the objective of the paper is concerns the search for the main conventional applications that could be followed to support the presence of new buildings placed in these places in a smart manner supposing that using techniques and tools being developed today to make complete high performance products is one of the main hypothesis that could be followed, also representing the multi functioning of any element of the space.

\section{The Measurement of the Main Aspects of Intelligence}

Referring to the intelligence in architecture there are three calls for it appearing in; smart materials, intelligent element and the smart building. As the aspects of intelligence all of them have to be deduced and analyzed.

\subsection{Smart Materials}

The world has recently undergone two materials ages, the plastics age and the composite age. In the midst of these two ages a new era has developed. This is the smart materials era. According to early definitions, smart materials are materials that respond to their environments in a timely manner. The definition of smart materials has been expanded to materials that receive, transmit, or process a stimulus and respond by producing a useful effect that may include a signal, which the materials are acting upon it. Some of the stimuli that may act upon these materials are strain, stress, temperature, chemicals (including $\mathrm{pH}$ stimuli), electric field, magnetic field, hydrostatic pressure, different types of radiation, and other forms of stimuli. The effect can be caused by absorption of a proton, of a chemical reaction, of an integration of a series of events, of a translation or rotation of segments within the molecular structure, of a creation and motion of crystallographic defects or other localized conformations, of an alteration of localized stress and strain fields, and of others. The effects produced can be a color change, a change in index of refraction, a change in the distribution of 
stresses and strains, or a volume change [4]. This ability to produce a useful effect refers to the characteristics of smart materials; we discover that they directly focus on their actuation events and the ability of prediction, immediate response to the environmental conditions. With applying this we can group smart materials into:

- Property change capability

- Energy exchange capability

- Reversibility

\subsection{An Intelligent Element}

Intelligent elements can enhance product performance. By improving the mechanical properties of a system through adaptive assimilation to actual environmental conditions. As the architectural design always involve integrated systems and materials, then the biggest potential Application of smart materials will result in to separate the specific components (The development of smart materials will be involved in a variety of components such as sensors, actuators, the shape-memory alloys and etc.), behaviors or indoor environment[5]

\subsection{Smart Buildings:}

It could be defined as the automation involved somehow that makes managing and operating buildings more efficient.

Smart Buildings LLC (a US-based engineering and design firm) offers this definition: "A smart building is the integration of building, technology, and energy systems. These systems may include building automation, life safety, telecommunications, user systems, and facility management systems. Smart buildings recognize and reflect the technological advancements and convergence of building systems, the common elements of the systems and the additional functionality that integrated systems provide. Smart buildings provide actionable information about a building or space within a building to allow the building owner or occupant to manage the building or space."

Standards-based. The Smart Buildings Institute (a new Texas non-profit that's developed a smart building certification process), describes a certified smart building as one that,

1. Provides actionable information regarding the performance of building systems and facilities;

2. Proactively monitors and detects errors or deficiencies in building systems;

3. Integrates systems to an enterprise business level for real-time reporting and management utilization of operations, energy and occupant comfort;

4. Incorporates the tools, technologies, resources, and practices to contribute to energy conservation and environmental sustainability."

According to the European Commission, "Smart buildings means buildings empowered by ICT (information and communication technologies) in the context of the merging Ubiquitous Computing and the Internet of Things: the generalization in incrementing buildings with sensors, actuators, micro-chips, micro- and Nano-embedded systems will allow to collect, filter and produce more and more information locally, to be further consolidated and managed globally according to business functions and services."

Classic tech-speak. Cisco emphasizes the multi syllabic when he says that smart building development focuses on "Identifying responsible practices in site location and materials selection for new construction; Defining and incorporating intelligent information 
infrastructure into the building architecture; Developing simple, flexible, and scalable network systems for buildings; Incorporating power-management for network system [6].

\subsection{The Main Aspects of Intelligence}

Finally we summarize that the smart or intelligent aspects mainly concern the production of the useful effect, acting as a clever system which does not stop performance, and maintaining Efficiency.

\section{Applying the Intelligent Aspects on the Integration of the new Building with the old one:}

The same aspects of intelligence summarized have to be measured within the building while integrating with the urban context, as they are as follows:

2.1 Production of the useful effect

2.2 Acting as a clever system and does not stop performance

\subsection{Efficiency}

\subsection{Production of the Useful Effect:}

This aspect refers to the performance which is the synonym of effectiveness this term concerns the degrees to which objectives are achieved and the extent to which targeted problems are solved. In contrast to efficiency, effectiveness is determined without reference to costs and, whereas efficiency means "doing the thing right," effectiveness means "doing the right thing."

Effectiveness is the capability of producing a desired result. When something is deemed effective, it means it has an intended or expected outcome, or produces a deep, bright impression [7]. The word effective is sometimes used in a quantitative way. On the other hand, is the ability to produce a desired amount of the desired effect, or success in achieving a given goal [8].

This aspect could be measured within the unique design, Functional effectiveness, Security, Energy effectiveness and the Smart actions.

\subsubsection{The Unique Design}

The architectural conceptual design should be unique and creative to achieve the objectives of the project. The conceptual vision should be in accordance to the importance and the significance of the building. As it must exploit individuality, uniqueness and the differences between places [9].As shown in London City Halls House (table: 1) 
Table (1) unique design of London City Hall

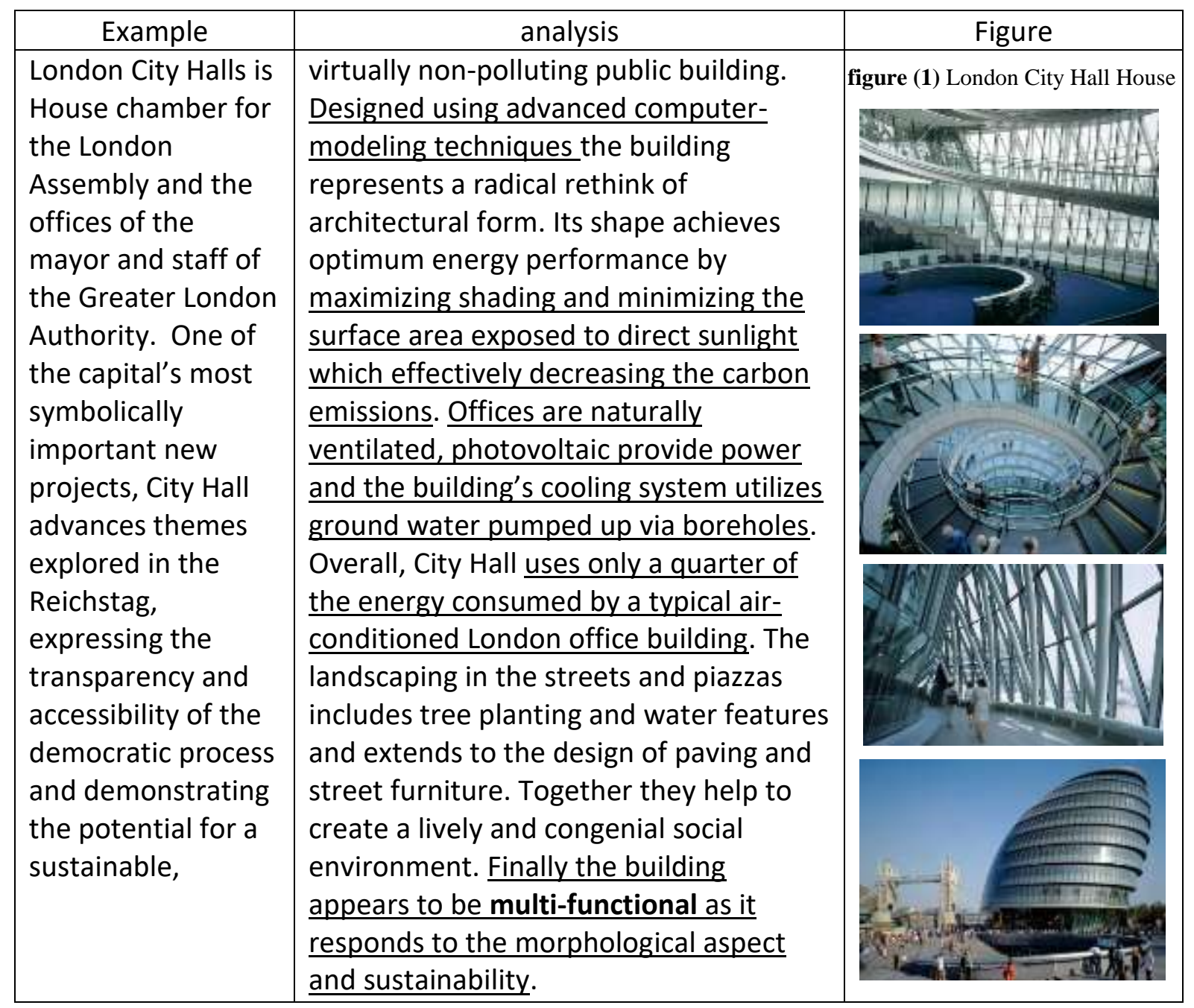

\subsubsection{Functional Effectiveness}

Whereas some references call it functional efficiency which is the functional relationship between spaces and the circulation, zoning of uses and functions should provide vitality, which encourages people to enter the building. (Table: 2 )

Table (2) Sainsbury Centre for visual art in .UK. By Norman foster,

\begin{tabular}{|l|l|}
\hline \multicolumn{1}{|c|}{ Example } & \multicolumn{1}{c|}{ analysis } \\
\hline $\begin{array}{l}\text { Sainsbury Centre for visual art in .UK. By } \\
\text { Norman foster, it is constructed to be a } \\
\text { multifunctioning building contains } \\
\text { galleries, a new education Centre, shop, } \\
\text { café, and other visitor amenities }\end{array}$ & $\begin{array}{l}\text { Mixed uses and variable activities that are well } \\
\text { distributed provide vitality [11]. The building } \\
\text { succeeded in achieving a certain goal which is } \\
\text { multifunctioning of the space . it integrates a number } \\
\text { of related activities within a single, light-filled space }\end{array}$ \\
&
\end{tabular}




\subsubsection{Security:}

Security can be classified into two phases as the first concerns the security inside the building itself and the second concerns the security of the whole physical urban context that the building represents a part of it.

2.1.3.1 Security inside the Building: The building should be characterized by security and safety. It should be provided by fire alarm and firefighting systems in addition to control and security systems [12].

2.1.3.2 .The Security of the Whole Physical Urban Context: the latest main urban conceptual refer to the attractive, intricate places related to the scale of people walking, not driving to give the sense of security and the feeling of well-being or comfort. So any building could be built newly has to agree with that conceptual [13].

\subsubsection{Energy Effectiveness:}

Within the hypothesis of using techniques and tools being developed today to make complete high performance products the energy effectiveness which is called in various references the energy efficiency concerns the following:

- Using renewable energy such as wind, sun, geothermal, etc.

- Use of smart technology: using technology to moderate energy and water use

As shown in Sage Gates head in UK. (Table:3)

Table (3) energy efficiency of Sage Gates by Norman foster,

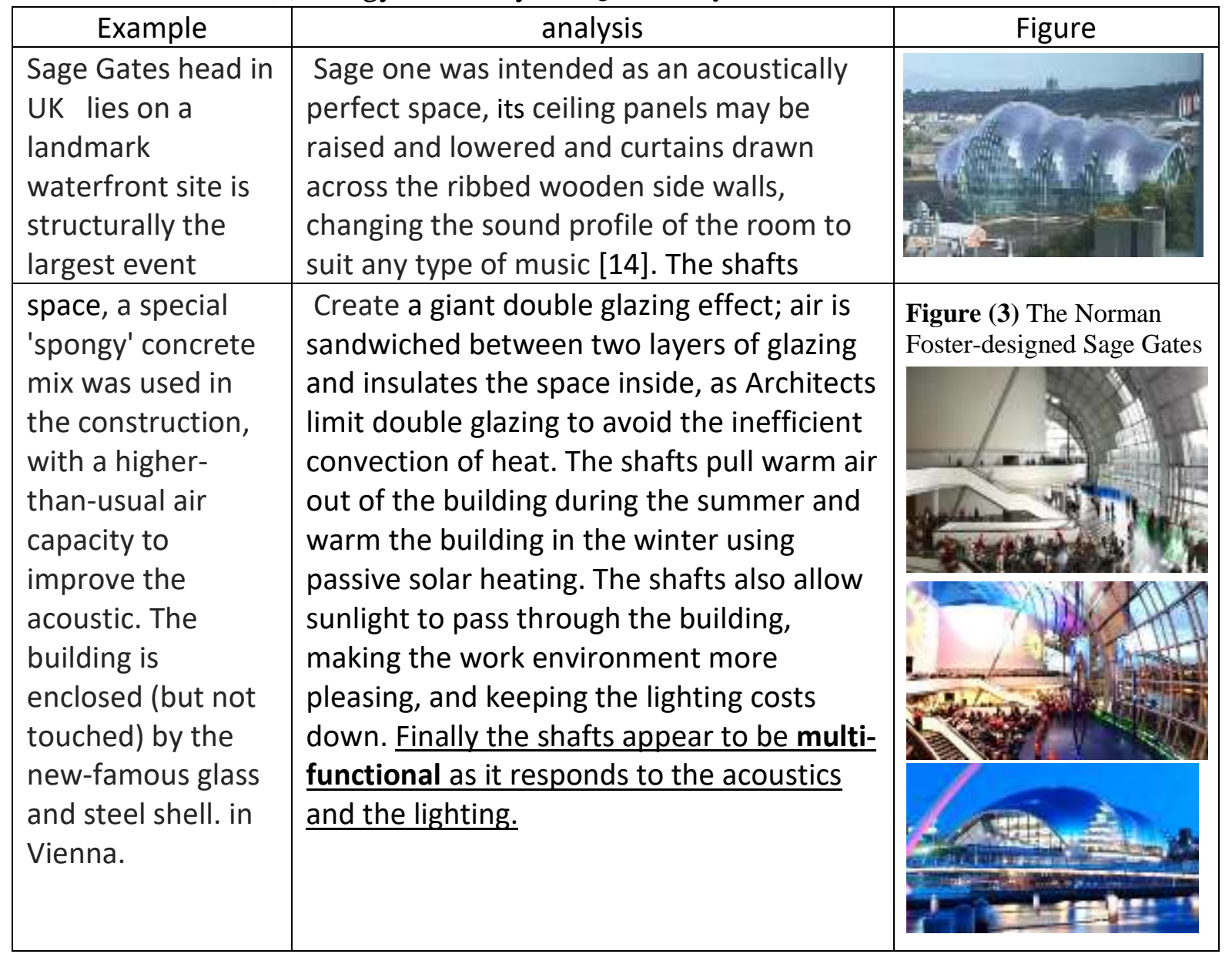




\subsubsection{Smart Action:}

The building should be known of its smart actions within the following:

-It should provide actionable information regarding the performance of building systems

-The presence of the proactively monitors which detect the errors or deficiencies in building systems.

-It should Integrate systems to an enterprise business level for real-time reporting and management utilization of operations, energy and occupant comfort.

- Incorporates the tools, technologies, resources, and practices to contribute to energy conservation and environmental sustainability see the example of Asian eco-cities rise to climate crisis later [15].

\subsection{Acting as a Clever System and Doesn't Stop Performance:}

This aspect could be measured within the continuity with nature and the flexibility with the urban context.

\subsubsection{The Continuity:}

The continuity could be divided into two sectors as the continuity while the Integration with the nature and the continuity through the Integration with the urban physical context.

2.2.1.1. Integration with the Nature: Lately, the equivalence of learning from the nature and using the nature for ecological accounting methods which results in making the nature visible and explicit as depending on Formal harmony and coherence with external context through transparency, continuity, and openness of formal surface to afford extension and communication with landscape. So concept of the integration with the nature could be directed as the following:

a- Making the Nature Visible and Explicit, depending on using intelligent glass over formal surface to control interior lighting quantity and heating loss or gain.

b- Using the Nature for Ecological Accounting Methods, depending on using open courtyard to increase climatic efficient, formal treatment like staggering, waving, interposition, and hierarchy to reduce heating loss or gain.

c- Formal Harmonize and Coherence with External Context through transparency, continuity, and openness of formal surface to afford extension and communication with landscape, efficient formal orientation, reducing the proportion of depth of formal building to supply more daylight [16].

\section{Example: Asian Eco-Cities Rise to Climate Crisis:}

Description: The Asian eco- cities Project is one of the world's largest greenhouse. Eco-cities, also known as sustainable cities, are designed with environmental considerations at their core. Such cities seek to reduce as much as possible their environmental impact and minimize the use of energy, food, and waste. The concept has gained popular recognition ever since the term was first coined by California-based planner Richard Register some 35 years ago, who defined it as a holistic approach where government, industry, people's needs and aspirations, nature, agriculture and the physical environment are "functionally integrated", The eco-city model: Practical, replicable, scalable Figure4. 
Figure (4) Asian eco-cities rise to climate crisis

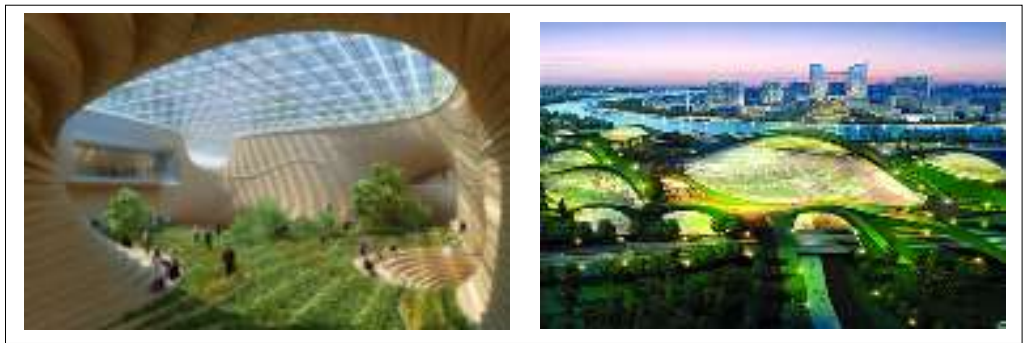

http://www.eco-business.com/news/liveable-cities-series-asian-eco-cities-rise-to-climate-crisis/

\section{Analysis:}

- $\quad$ Form: The core message of the project is one of sustainability, it was important to develop a design that could, regardless of size, be considered sustainable. The efficiency of spherical geometries is minimum surface area for maximum volume sounded like an economic strategy that was going to be hard to beat. These efficiencies extended beyond the structure and into the envelope and environmental systems. Spheres are minimal surfaces that have maximum volume. They allow direct sunlight to enter perpendicular to the surface at all times of the day, thus maximizing the free energy (Ecological Accounting Methods).

- Position: Maximizing solar penetration was a key target and knowing where this asset lay determined the optimal positions for the biome structures. The results of this mapping indicated that the design should be linear in profile with lean-to structures built against south-facing cliffs, a replicated foam geometries attached by linking bubbles in three dimensions, carefully following the solar boundaries whilst ensuring that the brief areas could be sustained (Ecological Accounting Methods).

- Learning from the Nature: One of the biggest concerns was the resolution of intersecting spherical geometries. As it results from studying nature for possible solutions and eventually came across a dragonfly's wing as a model for how minimal surfaces (Formal Harmonize and Coherence with External Context).

- $\quad$ Cladding Systems: Further effectiveness was gained when we began to assess the options available for transparent cladding systems. The design was developed using ETFE foil-a transparent Teflon foil system fabricated as triple-skin pillows inflated to 300 pounds per square inch. These pillows allow greater penetration of low-frequency ultraviolet light, are better thermal conductors, and weight less than 1 per cent of double-glazed glass panels. Maximum panel size on the biomes is 53 square meters, which greatly reduced the weight of primary steel structure and its subsequent shading effect [17]. (Making the Nature Visible and Explicit).

\subsubsection{The Integration with the Urban Physical Context:}

To achieve the proper urban solution with an urban scale, we need a clear appreciation of the urban grain and built form - what is sometimes called the morphological context. We also need to understand fully the local architectural typology - related to the uses and functions of the particular buildings. New proposals - Whether for a large piece of urban design or an individual building - must have a positive relationship to the existing morphology - by harmonizing with it, by adapting to it or, where there are clear reasons to do, by contrasting with it. The important thing is to take a positive design stance not just an 
arbitrary one [18] and this could be achieved by using the Regulating Plan and Form-Based Code*1 .As Form-based codes focus on building form and how it affects public spaces. By relating buildings back to the street and open spaces. This focus allows form-based codes to guide the creation of active, sustainable neighborhoods. Here are some of the more important aspects of form-based code.

a. Focus on Form: each building type will detail building and parking sitting, facade and use requirements, and height. The regulations frequently include acceptable ranges, such as minimum and maximum heights or a build-to zone rather than a setback. These ranges allow for flexibility in development, and there is reassurance in the level of predictability that they provide. Since each code is created based upon the preferences of the community, codes will differ among cities and among neighborhoods within cities. Based on these preferences, the facade requirements especially will vary in their level of detail. At a minimum, pedestrianoriented characteristics such as entrance location, transparency level, base type (treatment of the ground-story front facade), and cap type (including roof type) will be regulated, and a city may choose to include additional requirements [19].

Example: Dresden Museum of Military History: New York architect Daniel Libeskind has driven a pointed steel and glass fragment through the heart of the war museum in Dresden, which reopens on October 14 after a 22-year closure. Update 17/11/2011, Daniel Libeskind's winning design boldly interrupts the original building's symmetry. The extension, a massive, five-story 140-ton wedge of glass, concrete and steel, cuts through the 135-year-old former arsenal's structural order. A 98-foot high viewing platform provides breathtaking views of modern Dresden while pointing in the opposite direction toward the source of the fire-bombs, creating a dramatic space for reflection. "The dramatic extension is a symbol of the revival of Dresden from its ashes. It is about the neighboring between tradition and innovation, the new and the old. Dresden is a city that has been fundamentally altered; the events of the past are not just a footnote; they are central to the transformation of the city today."- Daniel Libeskind.

The (MHM) offers different perspectives on German military history. The architecture, the new thematic exhibition, and the redesigned permanent (chronological) exhibition represent both traditional and new forms of perception and expression. The neighboring between tradition and innovation, of old and new interpretations of military history, is the cornerstone of the new approach. [20] Figure 5.

\footnotetext{
* ' A Form-Based Code (FBC) is a means of regulating land development to achieve a specific urban form. Form-Based Codes foster predictable built results and a high-quality public realm by using physical form (rather than separation of uses) as the organizing principle, with a lesser focus on land use, through municipal regulations. A FBC is a regulation, not a mere guideline, adopted into city, town, or county law and offers a powerful alternative to conventional zoning regulation

Form-Based Codes are a new response to the modern challenges of urban sprawl, deterioration of historic neighborhoods, and neglect of pedestrian safety in new development. Tradition has declined as a guide to development patterns, and the widespread adoption by cities of single-use zoning regulations has discouraged compact, walkable urbanism. Form-Based Codes are a tool to address these deficiencies, and to provide local governments the regulatory means to achieve innovative objectives with greater certainty https://en.wikipedia.org/wiki/Form-based_code.
} 
Figure (5) the new addition is about the juxtaposition of tradition and innovation, of the new and the old.

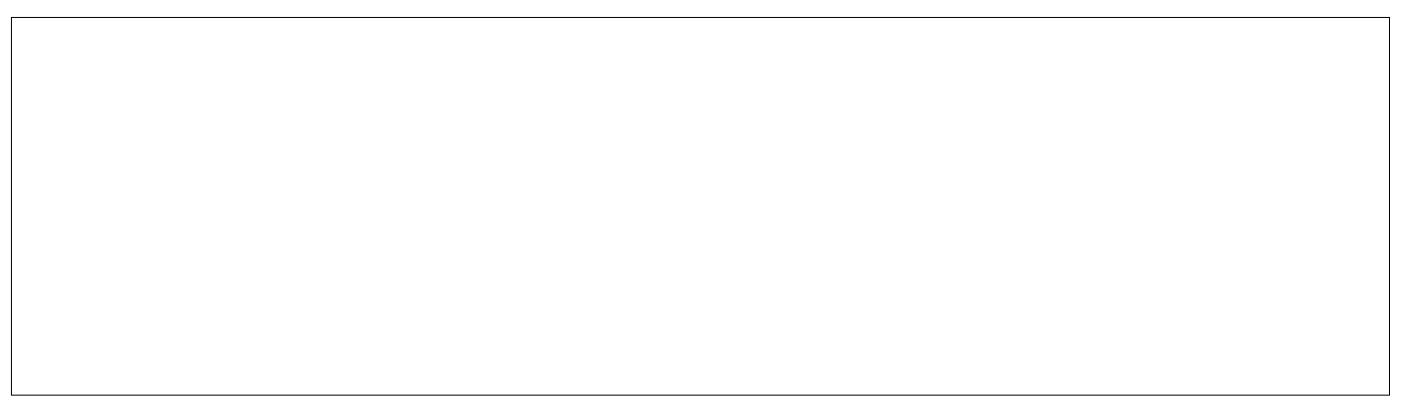

http://media2.picsearch.com/is?6L6kjpf4FUyAtioItb6cib9j9eP-4GopU8R7fQ8suxM\&height=341

B. Regulating Plan: districts are created, each allowing for the development of at least one building or open space type. Each district is mapped in the regulating plan, similar to a conventional zoning map; however, this is done by examining each parcel and block individually, and is favored in form-based codes not by establishing large strips of one type of district. Besides mapping the building and open space types, the regulating plan also details how the street types are developed in association with the building and opens space types [21].

Figure (6) Smart Growth Network and ICMA that serve as road map for states and communities that have recognized the need for smart growth.

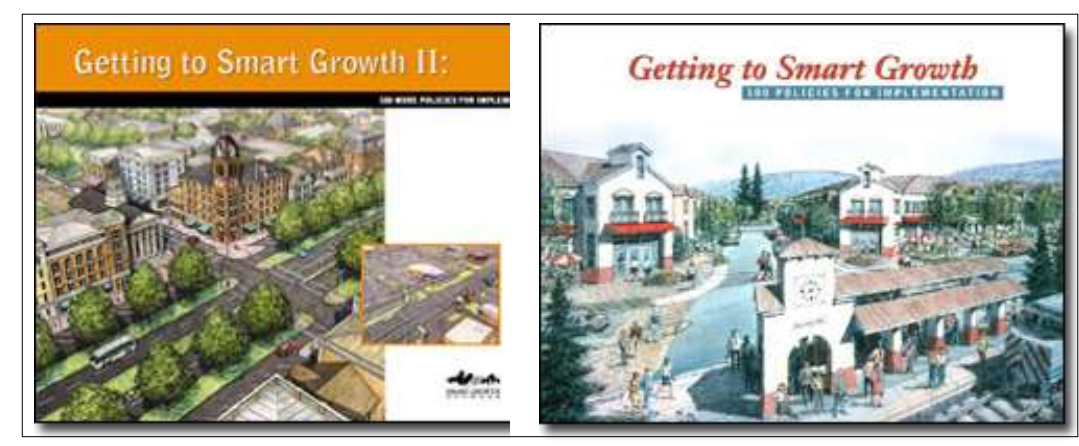

http://media1.picsearch.com/is?

The features that distinguish smart growth in a community vary from place to place. In general, smart growth invests time, attention, and resources in restoring community and vitality to center cities and older suburbs. New smart growth is more town-centered, is transit and pedestrian oriented, and has a greater mix of housing, commercial, and retail uses. It also preserves open space and many other environmental amenities.

\subsubsection{Flexibility:}

Adaptive buildings should be characterized by flexible functions, spaces, and internal furniture so that change could occur by time. And the structure used in this era is searching for replying this issue as shown in Telekom Malaysia Headquarters, Menara Telekom, in maize which is designed by Hijjas Kasturi Associates Figure 7, as the tower rises with a central core and two offset office curving office wings. The wings create open courtyards flanking each side of the tower core which support a series of 11 outdoor terraces facing to the southeast and the northwest. As one office wing tops out, a helipad takes over the set back with a large disc shaped cantilever extending out [22] 
Figure (7) Telekom Malaysia Headquarters, Menara Telekom, in malizia designed by Hijjas Kasturi Associates
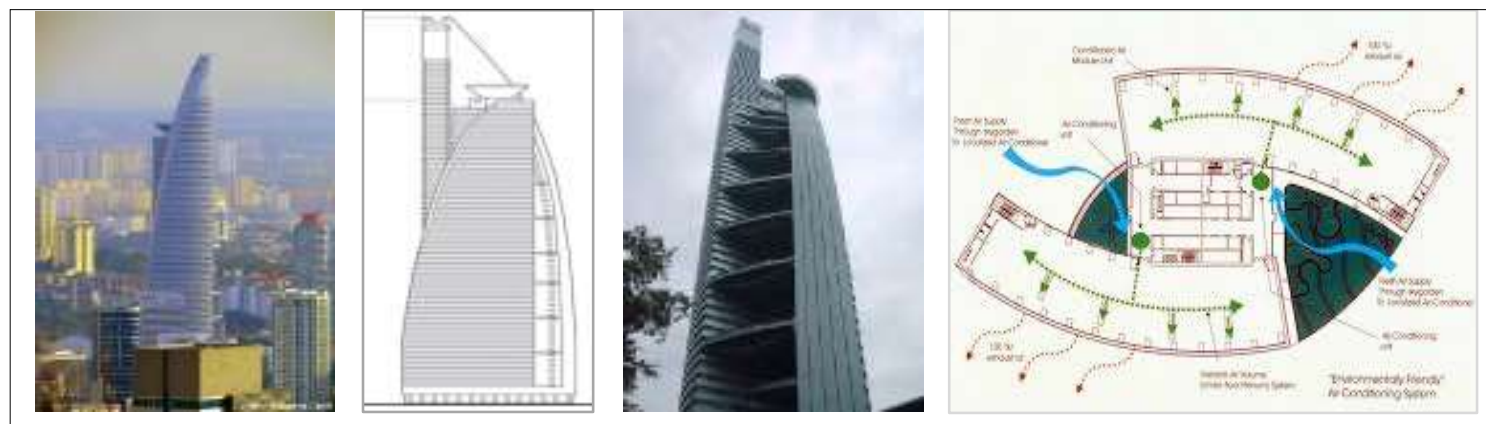

http://media1.picsearch.com/is?xajOGkokYxYC3Fwg6KOvEK86watAlFS885m2ZaNvJe8\&height=181

And also shown in prefabricated building which is designed according to the customers' need, mobile, economical, recyclable, and environmental. Figure 8.

Figure (8) the prefab building mobile, economical, recyclable, and environmental protective

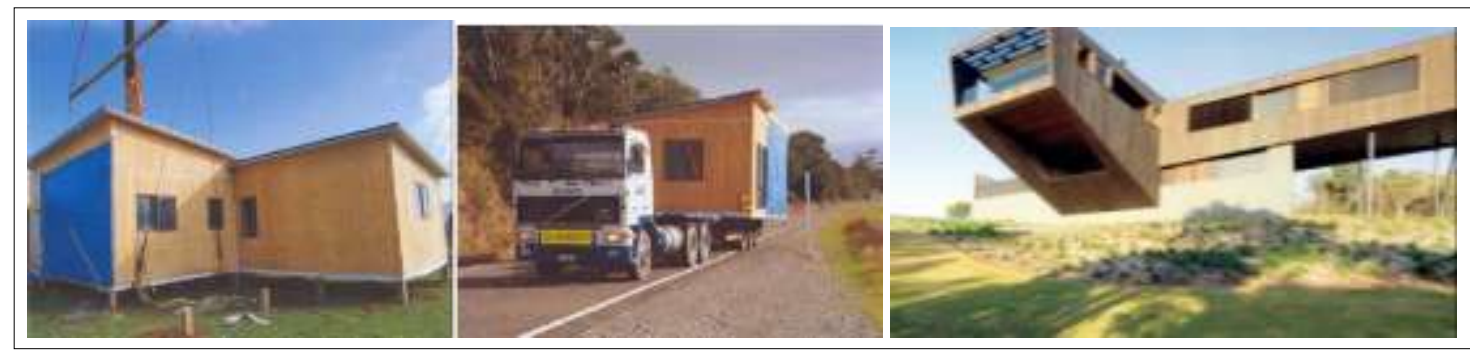

http://media1.picsearch.com/is?NSxluF_BYJu-OK8xeJsnuHt2z6Ku0m9sDCVVRveeHSo\&height=111

\subsection{Efficiency:}

In contrast to effectiveness, Efficiency refers to the cost as it means "doing the thing right". So it can be shown through the integrated systems for Green building standard, the Integrated Design, and the Marketing initiatives.

\subsubsection{Efficiency within Integrated Systems for Green Building Standard :}

It is one of a number of voluntary leadership standards for enhancing the environmental performance of buildings. It combines minimal fixed performance requirements with an optional menu of sustainable building practices. Sustainable urbanism concludes that society will inevitably move to require high performance building (HPB).as shown Asian eco- cities Project [19].

\subsubsection{Efficiency within Integrated Design:}

Integrated design is a hallmark of the green building movement. By optimizing the performance of a building as an entire system, this design approach can improve a building's performance at little or no added cost simply by shifting money within the project. A classic illustration is to reallocate a building's construction budget to specify more insulation and better windows and recoup some or most of those costs by buying a smaller, less expensive mechanical system. The resulting building will incur a small construction premium but will produce an acceptable return of investment on that premium, using far less energy and costing far less to operate as shown in The Asian eco- cities Project [19]. 


\subsubsection{Marketing Initiatives:}

Most heritage spaces or districts suffered from contemporary change in the downtown retail market as it is now economically and visually diminished. There is widespread public concern about its economic health and a widely Acknowledged recognition of the need for its revitalization to promote the district and attract new business to keep it economically sustainable to insure the sustained maintenance. So the overall objectives concerning such issue as shown in existing red wing downtown walking tour-Washington-includes the following:

(a) The revitalization of the Street as a focus of retail, commercial, and cultural activity.

(b) To encourage restoration of heritage buildings and storefronts.

(c) To attract market specialty retail, cultural, and entertainment uses at street level.

(d) To fill vacant space on upper floors and encourage conversion to residential use.

(e) To improve HRM's image \& marketing potential.

(f) To restore investor confidence and trigger private investment. [21].

As existing red wing downtown walking tour Fig.9 is an identifiable district within the downtown. It is well-recognized in the public consciousness as Halifax's existing main street. Its many Victorian, Edwardian and Early Modern commercial buildings give it a unique heritage character which is quite different from that of adjacent streets. The Red Wing Heritage Preservation Commission (HPC) has produced 28 podcasts featuring all of the existing buildings and sites featured in the Footsteps through Existing Red Wing walking tour booklet that are located in the Downtown and Heritage Mall Existing Districts. The narrated podcasts combine existing photographs, current photographs, video, maps, and other documents regarding Red Wing's history and the existing and architectural significance of each site. The Street is also recognized as the street which has suffered most from contemporary change in the downtown retail market, and the effects of traffic and transit. Once the bustling heart of the city, it is now economically and visually diminished. There is widespread public concern about its economic health and a widely acknowledged recognition of the need for its revitalization. There is a pressing need to re-establish private sector confidence in the street and create an environment which encourages private investment. There is a need to enhance its heritage character and physical attractiveness through building facade, storefront, and signage improvements, public realm developments, and sympathetic new buildings. There is also a need to expand commercial activity and to promote and market the street as a commercial destination.

Fig (9) the map of historic red wing downtown walking tour

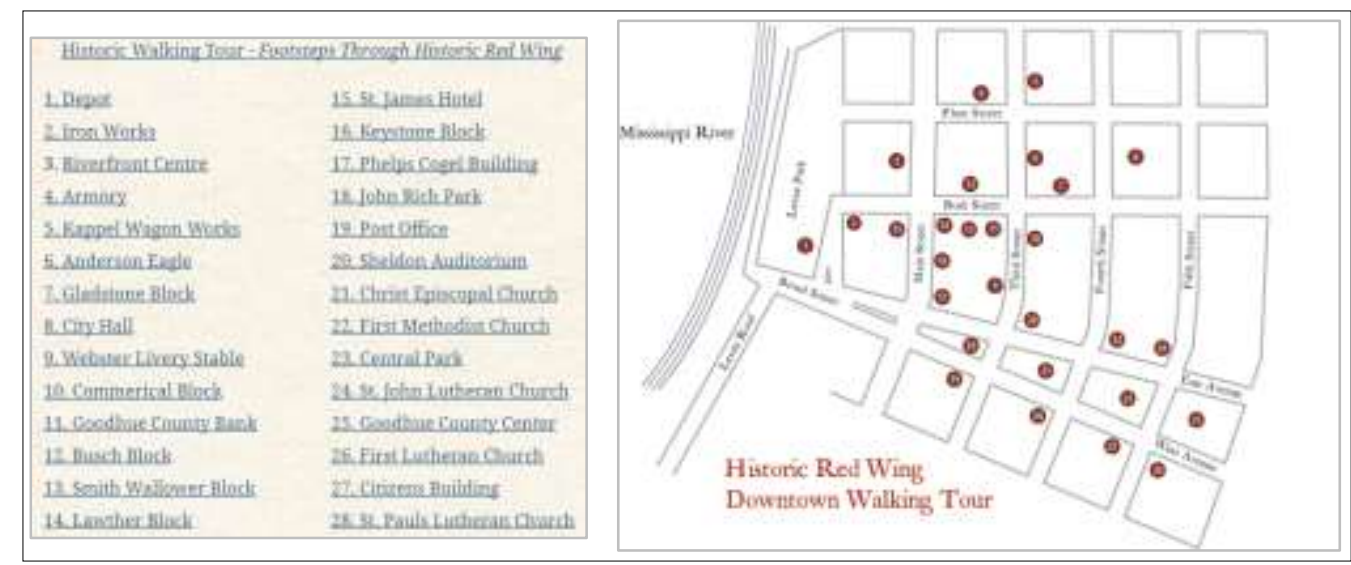




\section{Conclusions}

The aspects of intelligence varies and used in architecture but not by that way which can affect the urban context to make it sustainable specially while integrating the new building with the heritage one. And the morphology of forming the city will varies while using the supposed intelligent criterion.

The following table could be considered the collective list to illustrate the smart aspects used while integrating a new building with the heritage realm.

Table (4) illustrate the smart aspects used while integrating a new building with the existing realm.

\begin{tabular}{|c|c|c|c|}
\hline $\begin{array}{l}\text { The main } \\
\text { aspect }\end{array}$ & \multicolumn{3}{|c|}{ The criterion } \\
\hline \multirow{6}{*}{ 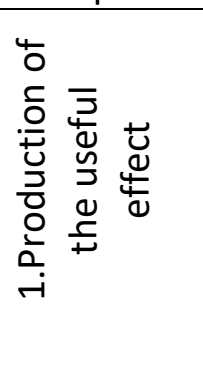 } & \multicolumn{3}{|c|}{ 1.1 The unique design } \\
\hline & \multicolumn{3}{|c|}{ 1.2 Functional effectiveness } \\
\hline & \multirow[t]{2}{*}{1.3 Security } & \multicolumn{2}{|c|}{ 1.3.1security inside the building } \\
\hline & & \multicolumn{2}{|c|}{$\begin{array}{l}\text { 1.3.2 The security of the whole } \\
\text { physical urban context }\end{array}$} \\
\hline & \multicolumn{3}{|c|}{ 1.4 Energy effectiveness } \\
\hline & \multicolumn{3}{|c|}{ 1.5 Smart actions } \\
\hline \multirow{6}{*}{ 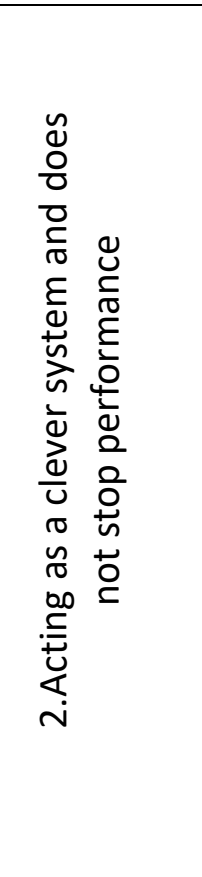 } & \multirow[t]{5}{*}{$\begin{array}{l}\text { 2.1The } \\
\text { continuity }\end{array}$} & \multirow[t]{3}{*}{$\begin{array}{l}2.1 .1 \text { Integration } \\
\text { with the nature }\end{array}$} & $\begin{array}{l}\text { a. Making the } \\
\text { nature visible and } \\
\text { explicit }\end{array}$ \\
\hline & & & $\begin{array}{l}\text { b. Using the } \\
\text { nature for } \\
\text { ecological } \\
\text { accounting } \\
\text { methods }\end{array}$ \\
\hline & & & $\begin{array}{l}\text { formal harmonize } \\
\text { and coherence } \\
\text { with external } \\
\text { context }\end{array}$ \\
\hline & & \multirow{2}{*}{$\begin{array}{l}\text { 2.1.2 The } \\
\text { Integration with } \\
\text { the urban } \\
\text { physical context }\end{array}$} & a. Focus on Form \\
\hline & & & b. Regulating Plan \\
\hline & \multicolumn{3}{|l|}{ 2.2Flexibility } \\
\hline \multirow{3}{*}{ 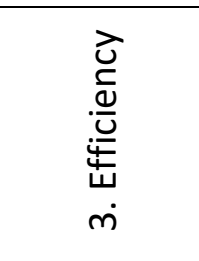 } & \multicolumn{3}{|c|}{$\begin{array}{l}\text { 3.1Efficiency within Integrated systems for } \\
\text { Green building standard }\end{array}$} \\
\hline & \multicolumn{3}{|c|}{ 3.2 Efficiency within Integrated Design } \\
\hline & \multicolumn{3}{|c|}{ 3.3 Marketing initiatives } \\
\hline
\end{tabular}

\section{Recommendations:}

- We call upon the architectural and planning community, professionals, decision makers and the government to acknowledge the urgent need to study, protect, and revive the existing 
realm and deal with it within a smart manner as this realm is an essential and progressive force to mediate the challenges of future urbanization.

- The existing Place is much more important than any individual architectural concept, furthermore a good understanding of the concept of the urban context is the key to solve problems of integration. So any research in such issue must highlight the importance the aspects of the era to establish a good city.

\section{References:}

[1]Mandy M. Ibrahim, 2000; A Comparative analytical study of the integration between new buildings and existing buildings. Aein Shams University, faculty of engineering. Egypt

[2]Diane Switzer, November 2010; heritage + sustainability, the Vancouver heritage foundation, British Columbia

[3]Schwartz, Mel M, 2002, Smart material - Encyclopedia, A Wiley-Inter science publication, New York.

[4]Harvey, James. A, 1998, Kirk-Othmer Encyclopedia of chemical technology, John Wiley \& Sons Inc., New York.

[5]2011 International Conference on Intelligent Building and Management Proc .of CSIT vol.5 2011 C 2011 IACSIT Press, Singapore

[6] Sakamura, K. "Torn Intelligent House"2004

[7]Dictionary.com, LLC. "Effectiveness I Define Effectiveness at Dictionary.com." Dictionary.com | Find the Meanings and Definitions of Words at Dictionary.com. 2011. Web. 28 Sept. 2011.

[8]STANDS4 LLC. "Effectiveness Synonym." Synonyms.net. 2011. Web. 28 Sept. 2011.

[9]Matthew Carmona and Steve Tiesdell, 2007; Urban Design Reader, OXFORD, Architectural Press

[10] Graeme Brooker and Sally Stone " Basics Interior Architecture: Context + Environment" Ava Publishing September 30, 2008

[11] Peter Larkham" Conservation and the City" Jossey-Bass; Routledge August 2, 1996

[12] Smith, F.; Peter, Architecture in a Climate of Change-A guide to sustainable design, Oxford OX2 8DP, 2005.

[13] Matthew Carmona and Steve Tiesdell, 2007; Urban Design Reader, OXFORD, Architectural Press.

[14] Innovation in Architecture Edited by Alan J.Brookes and Dominique Poole, 2004 by Spon Press.

[15] Lyons, Arthur, 2007, Materials for Architects and Builders, Elsevier, Oxford

[16] Innovation in Architecture Edited by Alan J.Brookes and Dominique Poole, 2004 by Spon Press.

[17] Matthew Carmona and Steve Ties dell, 2007; Urban Design Reader, OXFORD, Architectural Press.

[18] Douglas Farr" Sustainable Urbanism: Urban Design With Nature" Wiley; 1 edition November 16, 2007.

[19] Julia Horn castle, 2009; Barrington Street Heritage Conservation District Revitalization Plan, duly called meeting, June, 2009.the Municipal Clerk and under the Corporate Seal of the Halifax Regional Municipality. 


\section{Internet Sites:}

[20] http://en.wikipedia.org/wiki/Op\%C3\%A9ra_Nouvel

[21] http://www.greenbang.com/from-inspired-to-awful-8-definitions-of-smartbuildings 18078.html

[22] http:www.greet buildings.com//gbc.htm.

[23] http://legacy.skyscrapercenter.com/class-image.php/

[24] http://ilmec.en.alibaba.com/

[25] https://en.wikipedia.org/wiki/Form-based_code. 